\title{
Prevalence of periodontal conditions among public-funded dental patients in Australia
}

\author{
DS Brennan,* AJ Spencer,* GD Slade ${ }^{\dagger}$
}

\begin{abstract}
Background: The aims of this study were to describe periodontal health status by gender, type of care, geographic location and age and to investigate associations of these factors with tooth loss.

Methods: In 1995-96, state and territory dental services surveyed a random sample of 6,109 publicfunded patients. Dentists recorded oral health status at the initial visit of a course of care, using written instructions but without formal calibration. Periodontal status was assessed using the community periodontal index of treatment needs.

Results: Prevalence of periodontal conditions among dentate patients was higher among older, male, emergency and urban patients $\left(\chi^{2} ; \mathrm{p}<0.05\right)$. Agespecific edentulism was lower for male, emergency and urban patients $\left(\chi^{2} ; p<0.05\right)$. Numbers of missing teeth were lower for younger, non-emergency and urban patients (Anova; $\mathrm{p}<0.05$ ). Prevalence of periodontal pockets $6 \mathrm{~mm}$ or more was associated with gender, type of care, geographic location, age and number of missing teeth (logistic regression; $\mathrm{p}<0.05)$.

Conclusions: Prevalence of severe periodontal conditions was lower in 1995-96 compared with public-funded patients in 1984 and 1992-93, but prevalence of periodontal health remained lower than the general population in 1987-88. A survivor effect may result in lower recording of severe periodontal conditions among subgroups with higher tooth loss.
\end{abstract}

Key words: Periodontal status, CPITN, tooth loss, publicfunded care.

(Received for publication October 1998. Revised June 1999. Accepted for publication July 1999.

\section{Introduction}

Decreasing levels of self-reported measures of complete tooth loss have been reported among Australian adults. ${ }^{1-2}$ National level data documenting oral measures such as caries experience and periodontal conditions among adults were collected for the National Oral Health Survey of Australia in 1987-88. ${ }^{3}$

\footnotetext{
*AIHW Dental Statistics and Research Unit, Adelaide University.
} †Department of Dental Ecology, University of North Carolina.
Other adult oral health surveys in Australia have been confined to limited geographic regions, such as those conducted in Brisbane, ${ }^{4}$ Melbourne, ${ }^{5}$ and Adelaide. ${ }^{67}$ In addition to the restricted geographic scope of adult oral health surveys, there has also been little information regarding specific groups, such as health card holders, considered to be most at risk of the consequences of oral disease.

Health card holders are a low income group in the Australian population and the target group eligible for public-funded dental care. The health card system is administered by the Australian government and card holders include age pensioners and the unemployed. The 1992 National Health Strategy identified inequalities in oral health care and access to dental services as major issues in public health in Australia. ${ }^{8}$ Since then, oral health goals and targets for Australia have included reducing the number of people with untreated dental caries and reducing the prevalence of missing teeth and edentulism, specifically targeting people from low socioeconomic groups. ' However, periodontal conditions were not targeted and the lack of sufficient baseline data on the Australian population prevented the setting of oral hygiene targets. The public health significance of periodontal disease needs to be considered in relation to the substantial amount of tooth loss associated with periodontal disease, particularly among high-risk individuals. ${ }^{10}$

In 1984, using the community periodontal index of treatment needs (CPITN), periodontal assessments of public-funded patients were performed at Sydney's Westmead Hospital. ${ }^{11}$ Prevalence of periodontal disease was found to be high, but of mild to moderate severity, in most patients. Later findings on public-funded dental patients, from 1992-93, were based on New South Wales (NSW), Victoria and South Australian (SA) data. These findings indicated periodontal pocketing of $6 \mathrm{~mm}$ or more was highest among emergency patients aged 65 or older. ${ }^{12}$

The high cost of conducting clinical epidemiological examinations has been a barrier to oral health surveys. Australia has had only one national survey of oral health, conducted over a decade ago, which did not 
Table 1. Sociodemographic and visit details by state and territory

\begin{tabular}{|c|c|c|c|c|c|c|c|c|c|}
\hline & \multicolumn{9}{|c|}{ State or territory } \\
\hline & NSW & Vic & Qld & SA & WA & Tas & ACT & NT & All \\
\hline Number of patients & 874 & 1040 & 2628 & 753 & 160 & 359 & 26 & 269 & 6109 \\
\hline \multicolumn{10}{|l|}{ Dentate status \% } \\
\hline Dentate & 96.6 & 92.9 & 87.1 & 80.9 & 98.8 & 98.3 & 100.0 & 97.8 & 92.2 \\
\hline Edentulous & 3.4 & 7.1 & 12.9 & 19.1 & 1.3 & 1.7 & 0.0 & 2.2 & 7.8 \\
\hline \multicolumn{10}{|l|}{ Gender \% } \\
\hline Male & 45.3 & 47.1 & 45.7 & 43.3 & 37.5 & 38.9 & 26.9 & 39.0 & 44.5 \\
\hline Female & 54.7 & 52.9 & 54.3 & 56.7 & 62.5 & 61.1 & 73.1 & 61.0 & 55.5 \\
\hline \multicolumn{10}{|l|}{ Type of care \% } \\
\hline Emergency & 68.4 & 67.8 & 47.6 & 38.8 & 45.6 & 32.3 & 50.0 & 44.6 & 57.5 \\
\hline Non-emergency & 31.6 & 32.2 & 52.4 & 61.2 & 54.4 & 67.7 & 50.0 & 55.4 & 42.5 \\
\hline \multicolumn{10}{|l|}{ Location $\%$} \\
\hline Urban & 99.9 & 82.0 & 72.9 & 78.7 & 74.8 & 52.8 & 100.0 & 18.4 & 84.0 \\
\hline Rural & 0.1 & 18.0 & 27.1 & 21.3 & 25.2 & 47.2 & 0.0 & 81.6 & 16.0 \\
\hline \multicolumn{10}{|l|}{ Age of patient $\%$} \\
\hline $15-24$ & 8.1 & 12.3 & 13.0 & 6.5 & 9.9 & 14.9 & 19.2 & 21.2 & 10.7 \\
\hline $25-34$ & 17.5 & 15.6 & 15.1 & 12.8 & 20.8 & 27.8 & 19.2 & 35.9 & 16.7 \\
\hline $35-44$ & 15.7 & 18.1 & 15.7 & 16.8 & 20.1 & 20.1 & 19.2 & 21.2 & 16.9 \\
\hline $45-54$ & 13.4 & 14.7 & 11.4 & 9.5 & 12.6 & 12.0 & 19.2 & 12.0 & 12.8 \\
\hline $55-64$ & 19.4 & 18.0 & 15.2 & 16.9 & 14.5 & 11.5 & 3.9 & 6.2 & 17.0 \\
\hline $65+$ & 25.9 & 21.4 & 29.7 & 37.6 & 18.9 & 13.8 & 19.2 & 3.5 & 25.9 \\
\hline
\end{tabular}

include the Northern Territory (NT). ${ }^{3}$ There has also been limited documentation of the periodontal status of public patients. ${ }^{11-12} \mathrm{~A}$ monitoring survey approach, which utilises the initial clinical examination of a course of care by the treating clinician, has the advantage of reducing costs and enabling data to be collected on a large number of patients across a wide range of clinics. Such an approach is analogous to the use of routine records such as disease registers and death certificates in epidemiological studies. ${ }^{13}$ In this study, some of the limitations of record use were minimised by the researchers designing the collection/abstraction form, providing precise definitions of terms and employing abstracters/recorders familiar with the terminology.

The aims of this study were to first describe the prevalence of periodontal conditions among publicfunded dental patients, using the CPITN, by type of care, geographic location, gender and age based on a monitoring survey collected in all Australian states and territories. Given the reports of potential survivor effects observed for periodontal attachment loss associated with tooth loss among older adults, ${ }^{5}$ the second aim was to examine edentulism and numbers of missing teeth and determine if factors associated with periodontal conditions were also associated with tooth loss. The third aim was, using a multivariate statistical model, to examine the association of these factors with periodontal pocketing.

\section{Materials and methods \\ Collection procedures}

At the beginning of a public-funded course of care, data were collected from a random sample of adult patients. The target population consisted of adult card holders attending for public-funded dental care in all states and territories of Australia in 1995-96. Data were collected on dentist-assessed oral health status (coronal and root caries experience and sextant periodontal scores), patient characteristics (age and gender), visit details (type of care and geographic location of care) and services provided (service items provided during the course of care).

The mode of data collection varied between the states and territories, but was based on a recording system developed and tested in three states in 199293. ${ }^{14}$ In all the states and territories, except NSW, optical mark read (OMR) scan forms were used to record measures of oral health status. The remaining data on patient characteristics, visit details and service provision were either recorded on the same doublesided OMR form as the oral health data or were recorded on data files derived from computer-based management information systems (MIS) which were linked to oral health data recorded on single-sided OMR forms by clinic number, patient number and date of commencement of care. In NSW, only the United Dental Hospital of Sydney participated in the survey, using a manual forms system designed to be compatible with the data items collected on the OMR forms.

\section{Sampling}

Sampling was based on date of birth. A yield of approximately 3,570 patients was determined to obtain 119 people in each of six age groups. This provided prevalence estimates with a relative standard error of 40 per cent or less within five subgroups of an age group for key outcome measures as low as 5 per cent (for example, emergency patients receiving preventive services). Smaller yields were proposed for jurisdictions with smaller populations (Tasmania, the Australian Capital Territory $[\mathrm{ACT}]$ and the NT) in order to reduce the survey workload at clinics where patient flows were less. However, this limited the ability to make precise 
Table 2. Prevalence of worst periodontal condition among dentate patients by gender, type of care, geographic location and age

\begin{tabular}{|c|c|c|c|c|c|c|}
\hline & \multicolumn{6}{|c|}{ Worst periodontal condition } \\
\hline & $\begin{array}{c}\text { Total } \\
\text { people } n^{*}\end{array}$ & $\begin{array}{l}\text { Periodontal } \\
\text { health } \%\end{array}$ & $\begin{array}{c}\text { Gingival } \\
\text { bleeding \% }\end{array}$ & Calculus \% & $\begin{array}{l}\text { Pockets } \\
4-5 \mathrm{~mm} \%\end{array}$ & $\begin{array}{l}\text { Pockets } \\
6+\mathrm{mm} \mathrm{\%}\end{array}$ \\
\hline \multicolumn{7}{|l|}{ Gender† } \\
\hline Male & 2134 & 6.0 & 10.5 & 43.4 & 26.1 & 14.0 \\
\hline Female & 2570 & 8.0 & 13.9 & 43.4 & 24.1 & 10.6 \\
\hline \multicolumn{7}{|l|}{ Type of care $†$} \\
\hline Emergency & 2767 & 5.4 & 11.6 & 41.9 & 27.4 & 13.8 \\
\hline Non-emergency & 1936 & 9.6 & 13.4 & 45.6 & 21.7 & 9.8 \\
\hline \multicolumn{7}{|l|}{ Location $†$} \\
\hline Urban & 3914 & 5.7 & 11.5 & 42.9 & 26.8 & 13.1 \\
\hline Rural & 749 & 14.5 & 17.2 & 46.1 & 15.5 & 6.7 \\
\hline \multicolumn{7}{|l|}{ Age† } \\
\hline $15-24$ & 584 & 11.4 & 25.4 & 46.7 & 14.6 & 1.9 \\
\hline $25-34$ & 882 & 7.8 & 10.1 & 54.9 & 20.9 & 6.3 \\
\hline $35-44$ & 923 & 6.2 & 9.9 & 47.3 & 23.7 & 12.9 \\
\hline $45-54$ & 632 & 5.7 & 9.3 & 36.4 & 30.8 & 17.9 \\
\hline $55-64$ & 715 & 4.6 & 9.1 & 36.7 & 29.8 & 19.9 \\
\hline $65+$ & 922 & 6.7 & 12.6 & 36.3 & 30.5 & 13.9 \\
\hline All & 4707 & 7.1 & 12.4 & 43.4 & 25.0 & 12.1 \\
\hline
\end{tabular}

*Weighted number of dentate cases, rounded to the nearest integer. †(Chi-square; $\mathrm{p}<0.01)$.

age-specific estimates by another level of disaggregation in these states and territories. ${ }^{15}$

\section{Weighting}

The 1995 and 1996 national dental telephone interview surveys were utilised to weight the data, using the state- and territory-specific estimated number of adults who made their last annual visit to either a public dental clinic or a public-funded private practice. ${ }^{16}$ The national sample yields were weighted in proportion to the number of public-funded visits for each state or territory without inflating the sample size. Hence, all national estimates are adjusted for the different sample yield in each state or territory making the results representative of all health card holders seeking dental care in Australia. The data for NSW represent the distribution of patients sampled from the state capital of Sydney.

\section{Measurement approach}

The measurement approach adopted was consistent with a monitoring survey, with large numbers of clinics and examining dentists involved. There was no attempt at calibration of dentists, uniform written guidelines were used instead. In other places, as an alternative to conventional epidemiological surveys, such low-cost methods have been used to develop dental public health databases through the use of a large number of examiners. ${ }^{17}$ This approach is consistent with the aims of the survey - to provide an assessment of the oral health status of public-funded patients from the perspective of the service provider (the examining dentist who provides treatment). The approach was to supply dental services in all states and territories with copies of written instructions on the use of OMR examination forms and guidelines on coding and clinical definitions. These guidelines had been developed in conjunction with a steering committee comprised of representatives from state and territory dental services and the Commonwealth Department of Health and Family Services. The documentation consisted of a 44-page survey reference protocol for use by managers, a four-page coding instructions for patient and visit details and treatments and a four-page coding reference to oral health status for use at each clinic. The individual states and territories distributed these instructions to dentists involved in the provision of public-funded dental patient clinical care. These dentists collected data on the oral health status of patients at the beginning of a course of care during the survey period.

At the oral examination, dentists recorded items relating to dental prostheses, coronal and root caries experience and periodontal conditions. The analysis presented here relates mainly to periodontal conditions. Periodontal status was recorded using the CPITN. ${ }^{18-19} \mathrm{~A}$ score of 0 (periodontal health), 1 (gingival bleeding), 2 (calculus at any supra- or sub-gingival site), 3 (pocket of $4-5 \mathrm{~mm}$ ), or 4 (pocket of $6 \mathrm{~mm}$ or more) was scored for each dentate sextant or else an X (excluded) was recorded for edentulous or excluded sextants. All teeth in a sextant were examined and the most severe CPITN condition observed was recorded as the sextant score. Sextants were defined by tooth position, with molars and premolars making up four posterior sextants and canines and incisors making up two anterior sextants. Third molars were excluded unless they were functioning in place of second molars. Sextants were excluded (code X) when there were no teeth present or only one tooth that could be probed. If there was only one tooth in a sextant, the score for this single tooth could be carried forward for consideration in assessing the adjacent sextant. A periodontal probe was used to measure pocket depth (from gingival crest to the base 
Table 3. Prevalence of edentulism: gender, type of care, geographic location by age

\begin{tabular}{|c|c|c|c|c|c|c|c|c|c|c|}
\hline \multirow[b]{2}{*}{ Age } & \multicolumn{2}{|c|}{ Gender } & \multirow[b]{2}{*}{$\mathrm{p}$} & \multicolumn{2}{|c|}{ Type of care } & \multirow[b]{2}{*}{$\mathrm{p}$} & \multicolumn{2}{|c|}{ Location } & \multirow[b]{2}{*}{$\mathrm{p}$} & \multirow[b]{2}{*}{$\begin{array}{c}\text { All } \\
\%\end{array}$} \\
\hline & $\underset{\%}{\text { Male }}$ & $\begin{array}{c}\text { Female } \\
\%\end{array}$ & & $\begin{array}{c}\text { Emergency } \\
\%\end{array}$ & $\begin{array}{c}\text { Non-emergency } \\
\%\end{array}$ & & $\begin{array}{c}\text { Urban } \\
\%\end{array}$ & $\underset{\%}{\text { Rural }}$ & & \\
\hline $15-24$ & 0.2 & 0.5 & 0.53 & 0.2 & 0.7 & 0.34 & 0.3 & 0.8 & 0.37 & 0.4 \\
\hline $25-34$ & 0.4 & 0.7 & 0.61 & 0.4 & 0.8 & 0.39 & 0.4 & 1.2 & 0.22 & 0.6 \\
\hline $35-44$ & 1.8 & 1.7 & 0.92 & 0.6 & 3.3 & $* *$ & 1.3 & 2.9 & 0.10 & 1.7 \\
\hline $45-54$ & 5.0 & 4.1 & 0.57 & 1.9 & 8.0 & $* *$ & 3.5 & 11.0 & $* *$ & 4.5 \\
\hline $55-64$ & 9.1 & 10.1 & 0.62 & 6.6 & 13.2 & $* *$ & 8.4 & 16.1 & $* *$ & 9.6 \\
\hline $65+$ & 14.8 & 25.0 & $* *$ & 12.7 & 26.6 & $* *$ & 18.8 & 24.6 & 0.06 & 19.8 \\
\hline All & 7.1 & 8.5 & $*$ & 4.6 & 11.8 & $* *$ & 7.3 & 9.8 & $* *$ & 7.8 \\
\hline
\end{tabular}

$\mathrm{C}-\mathrm{M}-\mathrm{H} . \dagger$ Endentulism by gender, type of care and location, controlling for age: $\mathrm{p}=0.001$ for gender, type of care and location.

*Chi-square; $\mathrm{p}<0.05$.

*Chi-square; $\mathrm{p}<0.05$.

†C-M-H = Cochran-Mantel-Haenszel summary statistic.

of the pocket) and to detect subgingival calculus or bleeding. A CPITN probe with appropriate shaded markings was recommended in the written instructions as being most appropriate for this purpose but adoption of this recommendation depended on availability and local resource constraints.

\section{Analysis}

The sociodemographic characteristics of the sample were examined by state and territory. The prevalence of periodontal conditions and edentulism and numbers of missing teeth were then analysed by gender, type of care and geographic location, controlling for age. Proportions were tested using chi-square tests and means using analysis of variance. ${ }^{20}$

The prevalence of periodontal conditions is reported as the worst sextant CPITN condition for a dentate patient. Numbers of missing teeth refer to those recorded as missing due to caries or periodontal conditions. Analyses of missing teeth were restricted to examinations which had two or less invalid tooth status codes (for example, blank or multiple codes) out of the maximum of 32 , with the 6.3 per cent of dentate patients who had three or more invalid tooth status codes excluded. Type of course of care was defined as emergency if relief of pain was the reason for which the care was initiated; other types of care such as general scheduled care and screening visits were classified as non-emergency. Based on the residential postcode of the patient, geographic location was classified as urban or rural. ${ }^{21}$

Logistic regression was used to analyse the presence of $6 \mathrm{~mm}+$ pockets by gender, type of care, geographic location, age and number of missing teeth. ${ }^{22}$ The dependent variable was dichotomous, coded as 1 for dentate patients who had $6 \mathrm{~mm}+$ pockets in at least one sextant, otherwise they were coded as 0 . Sets of indicator variables coded as either 1 or 0 were used as independent variables for gender (reference: female), type of care (reference: non-emergency), geographic location (reference: urban), age (reference: 65+) and number of missing teeth (reference: no missing teeth).

\section{Results \\ Sample characteristics by state or territory}

Six thousand one hundred and nine patients were available for analysis (Table 1). The sample yields varied between states and territories, ranging from 26 in the ACT up to 2,628 in Queensland. Variation in sample yields by state and territory reflected differences in patient flows and logistical difficulties such as commencement times for implementing the survey and range of survey sites covered, reducing sampling efficiency. The total yield exceeded the 3,570 examinations required to provide acceptable precision when aggregated at the national level. However, this sample yield limits the level of precision possible when disaggregating age-specific estimates at the level of states and territories. Although the sample yield for the ACT was small (0.4 per cent of the total yield), this territory, when weighted, only comprised 1.3 per cent of public patients and comparisons of analyses which excluded these patients revealed this had little effect on the estimates or patterns of association observed, hence these patients were retained in the analyses.

Overall, dentate patients comprised 92.2 per cent of the sample - ranging from 80.9 per cent in SA, 87.1 per cent in Queensland and over 92 per cent in the other states and territories. Males comprised 44.5 per cent of the sample - ranging from 26.9 per cent in the ACT to 47.1 per cent in Victoria. Emergency courses of care comprised 57.5 per cent overall - ranging from 32.3 per cent in Tasmania to 38.8 per cent in SA and over 44 per cent in the other states and territories. The percentage of care at urban locations ranged from 18.4 per cent in the NT to 52.8 per cent in Tasmania and was over 72 per cent in the other states and territory. The high percentage of urban locations for NSW reflects the fact that all data were from the United Dental Hospital of Sydney. Overall, most of the patients were in the $65+$ age group (25.9 per cent) - this pattern was observed in NSW, Victoria, Queensland and SA. Younger age distributions were observed for Western Australia (WA), Tasmania and the NT where the highest percentage of patients were in the 25-34 age group. The 
Table 4. Numbers of missing teeth among dentate patients: gender, type of care and geographic location by age

\begin{tabular}{|c|c|c|c|c|c|c|c|}
\hline \multirow[b]{2}{*}{ Age } & \multicolumn{2}{|c|}{ Gender } & \multicolumn{2}{|c|}{ Type of care } & \multicolumn{2}{|c|}{ Location } & \multirow[b]{2}{*}{$\begin{array}{c}\text { All } \\
\text { Mean (se) }\end{array}$} \\
\hline & $\begin{array}{c}\text { Male } \\
\text { Mean (se) }\end{array}$ & $\begin{array}{c}\text { Female } \\
\text { Mean (se) }\end{array}$ & $\begin{array}{l}\text { Emergency } \\
\text { Mean (se) }\end{array}$ & $\begin{array}{c}\text { Non-emergency } \\
\text { Mean (se) }\end{array}$ & $\begin{array}{c}\text { Urban } \\
\text { Mean (se) }\end{array}$ & $\begin{array}{c}\text { Rural } \\
\text { Mean (se) }\end{array}$ & \\
\hline $15-24$ & $0.7(0.1)$ & $0.6(0.1)$ & $0.7(0.1)$ & $0.6(0.1)$ & $0.7(0.1)$ & $0.4(0.1)$ & $0.6(0.1)$ \\
\hline $25-34$ & $1.7(0.2)$ & $1.8(0.1)$ & $1.7(0.1)$ & $1.8(0.2)$ & $1.7(0.1)$ & $2.0(0.2)$ & $1.7(0.1)$ \\
\hline $35-44$ & $3.6(0.3)$ & $3.3(0.2)$ & $3.7(0.2)$ & $3.2(0.2)$ & $3.3(0.2)$ & $4.1(0.4)$ & $3.5(0.2)$ \\
\hline $45-54$ & $5.0(0.4)$ & $4.8(0.3)$ & $5.1(0.3)$ & $4.5(0.4)$ & $4.8(0.3)$ & $5.6(0.6)$ & $4.9(0.2)$ \\
\hline $55-64$ & $6.8(0.4)$ & $6.8(0.4)$ & $7.2(0.4)$ & $6.2(0.4)$ & $6.8(0.3)$ & $7.1(0.6)$ & $6.8(0.3)$ \\
\hline $65+$ & $8.0(0.3)$ & $8.8(0.4)$ & $8.8(0.4)$ & $7.9(0.4)$ & $8.2(0.3)$ & $9.8(0.7)$ & $8.4(0.3)$ \\
\hline All & $4.7(0.1)$ & $4.2(0.1)$ & $4.5(0.1)$ & $4.4(0.1)$ & $4.4(0.1)$ & $4.6(0.2)$ & \\
\hline \multirow[t]{5}{*}{ Anova: } & Factor & $\mathrm{p}$ & Factor & $\mathrm{p}$ & Factor & $\mathrm{p}$ & \\
\hline & Age & $* *$ & Age & $* *$ & Age & $* *$ & \\
\hline & Gender & 0.70 & Type of care & $* *$ & Location & $*$ & \\
\hline & Interaction & 0.49 & Interaction & 0.43 & Interaction & 0.32 & \\
\hline & R-sq: 0.184 & & R-sq: 0.186 & & R-sq: 0.185 & & \\
\hline
\end{tabular}

*Anova; $\mathrm{p}<0.05$.
$*$ Anova; $\mathrm{p}<0.01$

small number of cases in the ACT makes the age distribution difficult to interpret.

\section{Prevalence of periodontal conditions by gender, type of care, geographic location and age}

The prevalence of periodontal conditions presented in Table 2 showed significant variation by gender, type of care, geographic location and age. Comparing male with female patients, fewer males presented with CPITN conditions of periodontal health $(6$ per cent vs 8 per cent) and a higher percentage of males presented with pockets $6 \mathrm{~mm}$ or more (14 per cent vs 10.6 per cent). In patients attending for emergency as opposed to non-emergency care, fewer emergency patients presented with poor periodontal health (5.4 per cent vs 9.6 per cent) but more emergency patients presented with pockets $4-5 \mathrm{~mm}$ (27.4 per cent vs 21.7 per cent) and $6 \mathrm{~mm}$ or more (13.8 per cent vs 9.8 per cent).

A lower percentage of urban patients, compared with rural patients, presented with poor periodontal health (5.7 per cent vs 14.5 per cent) but urban patients presented with higher percentages of pockets $4-5 \mathrm{~mm}$ (26.8 per cent vs 15.5 per cent) and $6 \mathrm{~mm}$ or more (13.1 per cent vs 6.7 per cent). There was a trend toward lower levels of periodontal health and higher percentages of pocketing in older patients. The best periodontal health was observed in the 15-24 age group, while the highest percentage of pockets $4-5 \mathrm{~mm}$ was observed in the 45-54 and 65+ age groups and the highest percentage of pockets $6 \mathrm{~mm}$ or more was observed in the 55-64 age group. The trends by age suggest there is a need to control for age when making other comparisons, hence the analysis of periodontal conditions by sex, type of care and location was repeated controlling for age.

The results pattern indicates prevalence of periodontal conditions varies by age, gender, type of care and geographic location. However, some of these patterns may reflect patterns of tooth loss. If teeth have been removed due to periodontal problems, then a history of extractions may obscure the distribution of periodontal conditions.

\section{Edentulism by gender, type of care and geographic location, controlling for age}

In Table 3, it is shown the percentage of edentulous patients varies significantly by gender, type of care and geographic location. Among patients aged $65+$, males had lower percentages of edentulism compared with females. Emergency care patients had lower percentages of edentulism compared with non-emergency patients for all age groups 35-44 and older. For the age groups 45-54 and 55-64, patients at urban locations had lower percentages of edentulism compared with rural locations. These results suggest an inverse relationship between edentulism and prevalence of periodontal pockets, with those groups which tended to have a higher prevalence of periodontal pockets (for example, males, emergency care patients, patients at urban locations) having lower rates of edentulism.

\section{N umbers of missing teeth by gender, type of care and geographic location, controlling for age}

Table 4 shows there were significant differences in mean numbers of missing teeth by gender, type of care and geographic location. The mean number of missing teeth increased across older age groups, from 0.6 for 15-24 year olds to 8.4 for those aged 65 or more. Nonemergency patients presented with fewer missing teeth than emergency patients and urban patients had fewer missing teeth than rural patients. These findings for missing teeth confirm the pattern seen for prevalence of periodontal pockets and edentulism by type of care and geographic location. 
Table 5. Logistic regression model of prevalence of $6+\mathrm{mm}$ periodontal pockets among dentate patients by gender, type of care, geographic location, age and numbers of missing teeth

\begin{tabular}{|c|c|c|c|c|}
\hline & \multicolumn{4}{|c|}{$95 \%$ confidence interval } \\
\hline & Odds ratio & Lower bound & Upper bound & $\mathrm{p}$ \\
\hline \multicolumn{5}{|l|}{ Gender } \\
\hline Male & 1.33 & 1.10 & 1.60 & $* *$ \\
\hline Female (reference) & - & - & - & \\
\hline \multicolumn{5}{|l|}{ Type of care } \\
\hline Emergency & 1.60 & 1.31 & 1.95 & $* *$ \\
\hline Non-emergency (reference) & - & - & - & \\
\hline \multicolumn{5}{|l|}{ Location } \\
\hline Urban & 1.67 & 1.22 & 2.28 & $* *$ \\
\hline Rural (reference) & - & - & - & \\
\hline \multicolumn{5}{|l|}{ Age } \\
\hline $15-24$ & 0.12 & 0.06 & 0.23 & $* *$ \\
\hline $25-34$ & 0.41 & 0.29 & 0.58 & $* *$ \\
\hline $35-44$ & 0.92 & 0.69 & 1.21 & 0.53 \\
\hline $45-54$ & 1.21 & 0.91 & 1.62 & 0.19 \\
\hline $55-64$ & 1.40 & 1.07 & 1.84 & * \\
\hline $65+($ reference $)$ & - & - & - & \\
\hline \multicolumn{5}{|l|}{ Missing teeth } \\
\hline None (reference) & - & - & - & \\
\hline $1-21$ & 1.29 & 1.05 & 1.57 & * \\
\hline $22+$ & 0.88 & 0.51 & 1.54 & 0.66 \\
\hline
\end{tabular}

$* \mathrm{p}<0.05$.

\section{Multivariate associations of periodontal pockets by gender, type of care, geographic location, age and number of missing teeth}

A multivariate logistic regression analysis was performed to assess the associations of gender, type of care, geographic location, age and number of missing teeth with prevalence of periodontal pockets of $6 \mathrm{~mm}$ or more. In cases of incidence of periodontal pockets of $6 \mathrm{~mm}$ or more, Table 5 shows males had 1.33 times more periodontal pockets than females; emergency care patients 1.60 times more periodontal pockets than nonemergency patients; patients at urban locations 1.67 times more periodontal pockets than rural locations; patients aged 15-24 and 25-34 0.12 and 0.41 times more periodontal pockets respectively than patients aged 65 or more; patients aged 55-64 1.21 times more periodontal pockets than patients aged 65 or more, and patients with 1-21 missing teeth 1.29 times more periodontal pockets than those with no missing teeth. These findings indicate that, controlling for age, there are independent associations of gender, type of care and geographic location with prevalence of periodontal pockets as well as an effect by number of missing teeth among dentate patients.

\section{Discussion \\ Limitations}

This study was performed as a monitoring survey rather than an epidemiological survey. With the large numbers of clinics and examiners involved, there was no attempt at calibration of dentists or measurement of reliability. However, this is consistent with the approach of the survey, which sought to estimate the oral health of public-funded patients from the perspective of the service providers (the examining dentists). The use of general practitioners to collect epidemiological data has been investigated previously in the UK, ${ }^{23}$ where it was found measures such as mean numbers of filled teeth, sound teeth and the proportion of patients with 21 or more teeth were all similar to those found in the 1988 UK national survey of oral health. It was concluded the collection of data by general practitioners was feasible and had construct and internal validity. However, the researchers cautioned that the findings on a convenience sample of regularly attending adults could not replace traditional adult dental health surveys. While collection of DMFT data may differ from CPITN where estimation of probing depths can differ due to factors such as probe size, probe type, probing force and clinical experience, it has been collected in previous large scale surveys in Australia and the US which involved the use of a large number of examiners. ${ }^{3,17}$ In such cases, measurement instruments were selected which were practical, objective, reliable and easy to teach.

On practical and logistical grounds, the use of a large number of clinics and examiners precluded the measurement of reliability through duplicate examinations, which could adversely affect the validity of the data. Due to the increased probability of diagnostic errors, the use of a large number of examiners is not generally recommended for clinical trials or epidemiological surveys. ${ }^{17}$ The fact that only a small part of the total sample is contributed per examiner should reduce the effect of any systematic errors. ${ }^{17}$ However, despite the technical drawbacks of using a large number of examiners, the need for lowcost methods stems from the high cost of oral health surveys; therefore the value of the obtained data should 
be balanced against the perceived quality and cost of the data. Additionally, there is a need to consider the relevance of the data. While large numbers of examiners create technical difficulties in calibration and reliability measurement, the data obtained reflects the judgement of those responsible for treating the patient. This does not necessarily reflect a standard epidemiological measurement and hence may limit the ability to compare such data with traditional epidemiological surveys as differences may reflect perceptions of clinicians rather than a calibrated standard. Trends and patterns within such a data-set are likely to be robust, but there could be some drift in the point estimates. Therefore, conclusions drawn from such data should be supported through traditional epidemiological approaches involving small numbers of calibrated examiners.

\section{Target population}

The target population in this study was health card holders, a low income group. Hence, these results are not intended to be representative of the Australian population. It is expected that health card holders would have higher levels of disease and more untreated disease. These findings are restricted to health card holders who are eligible for care and have obtained such care. This group is most relevant for the purpose of assessing the oral health status of existing patients receiving public-funded care and cannot be generalised to the larger population of health card holders.

\section{Comparisons with other studies}

Comparisons of the prevalence of periodontal conditions can be made with other Australian studies of public-funded dental patients. Compared with the 1984 Sydney study, ${ }^{11}$ in this study there was a slightly lower percentage of periodontal pockets. For example, in this study, among those $65+, 30.5$ per cent versus 38 per cent in the Sydney study had pockets $4-5 \mathrm{~mm}$, and 13.9 per cent in this study had pockets $6 \mathrm{~mm}$ compared with 15 per cent in the Sydney study. The high prevalence of periodontal disease from the Sydney study was associated with the low socio-economic status of the patients. The present study also showed a lower prevalence of periodontal pockets compared with public-funded patients from NSW, Victoria and SA in 1992-93. For example, in this study, among those 65+, 24.4 per cent had pockets of $4-5 \mathrm{~mm}$ and 17.4 per cent had pockets of $6 \mathrm{~mm}$ or more. ${ }^{12}$ These comparisons could point to improved periodontal status between the study periods or to different prevalence levels among the successively wider population subgroups. Differences in diagnostic judgement could prevail as large numbers of uncalibrated examiners were used in the present study and in the findings reported from 1992-93. However, the trend toward improved periodontal health was confirmed in an independent Melbourne study. ${ }^{24}$ A 1985-90 longitudinal study of a random household sample of Melbourne adults indicated a trend toward improved periodontal health. ${ }^{24}$ However, the public-funded patients in the present study had inferior periodontal status compared with a 1987-88 study of the general population. ${ }^{3}$ For example, poorer periodontal health was observed among 15-19 year old public-funded patients in 199596 (17.1 per cent) compared with the $1987-88$ survey figure of 44 per cent.

\section{CPITN and tooth loss}

The higher percentage of periodontal pockets observed in males and those from urban locations in this study of public-funded dental patients is consistent with the 1987-88 general population data. ${ }^{3}$ It was also noted in these data that edentulism was lower for males and for people who lived in capital cities. A similar pattern by gender for periodontal attachment loss and edentulism has also been observed in an SA study of people aged over 60.7 Such findings point to an association between tooth loss and prevalence of recorded periodontal conditions.

A number of studies reported weaknesses - such as lack of universal validity underlying hierarchical principles and problems underestimating deep pocket prevalence associated with the partial recording approach - in the CPITN as an epidemiological tool. ${ }^{25}$ Measurement of pocket depth may also underestimate disease severity due to gingival recession with increasing age, as well as any confounding by tooth loss. $^{26}$ It may be that tooth loss can also distort prevalence measures derived from the CPITN. In the present study, the higher prevalence of severe periodontal conditions among urban patients seems paradoxical when patients in urban locations have been reported to have lower caries experience and a more favourable pattern of service-mix. ${ }^{16,27}$ However, in the present study, patients from urban locations had a lower percentage of edentulism as well as lower mean numbers of missing teeth among the dentate. There was a higher prevalence of severe periodontal disease in emergency patients, a low percentage of edentulous patients attended as emergency patients but there were slightly higher mean numbers of missing teeth among the dentate. Male patients also had a higher prevalence of severe periodontal disease and a low percentage of edentulous patients attended as emergency patients but there was no significant difference in mean numbers of missing teeth among the dentate.

This pattern suggests, in some instances, the recording of the prevalence of periodontal conditions affected by edentulism may also be influenced by the number of missing teeth. Prevalence of periodontal conditions and survival of teeth have been recognised as potential problems in older adults where the prevalence of periodontal disease is likely to be underestimated to some degree in association with the number of teeth lost. ${ }^{10}$ 


\section{Conclusions}

Prevalence of severe periodontal conditions recorded in 1995-96 using the CPITN was lower for publicfunded patients compared with previous surveys of public-funded patients (1984 and 1992-93) from restricted geographic locations in Australia. However, prevalence of periodontal health was still lower among public-funded patients in 1995-96 compared with that observed for the general population in 1987-88. These findings should be supported through standard oral epidemiological approaches using small numbers of calibrated examiners. The variation in prevalence of periodontal conditions between subgroups of users of public-funded dental care by geographic location and type of course of care was also associated with levels of tooth loss. This suggests a survivor effect may operate among subgroups with higher tooth loss resulting in lower recording of prevalence of severe periodontal conditions.

\section{Acknowledgements}

This research was supported by a grant to the Australian Institute of Health and Welfare from the Commonwealth Department of Health and Family Services. The assistance of state and territory dental services and participating private practitioners in the collection of these data is acknowledged.

\section{References}

1. Dental health (persons aged 15 years or more) February-May 1979. Canberra: Australian Bureau of Statistics.

2. Carter KD. National dental telephone interview survey, 1995. Adelaide: AIHW Dental Statistics and Research Unit, Adelaide University.

3. Barnard PD. National oral health survey of Australia, 1987-88. Canberra: Australian Government Publishing Service, 1993.

4. Powell RN, McEniery TM. The Brisbane statistical division survey of adult dental health, 1984. 3. Dental health status and treatment needs. Aust Dent J 1988;33:109-115.

5. Spencer AJ, Wright FAC, Brown DF, et al. A socio-dental study of adult periodontal health: Melbourne 1985. Melbourne: The University of Melbourne, 1988.

6. Mount G, Walker B, Roder D. Dental health and treatment needs of middle-aged and older patients attending 21 general practitioners. Aust Dent J 1987;32:166-170.

7. Slade GD, Spencer AJ. Periodontal attachment loss among adults aged $60+$ in South Australia. Community Dent Oral Epidemiol $1995 ; 23: 237-242$

8. National health strategy. Improving dental health in Australia. Background paper No 9. Canberra: Department of Health, Housing and Community Services, 1992.

9. Nutbeam D, Wise M, Bauman A, Harris E, et al. Goals and targets for Australia's health in the year 2000 and beyond. Canberra: Australian Government Publishing Service, 1993.

10. Beck JD, Loe H. Epidemiological principles in studying periodontal diseases. Periodontology 2000 1993;2:34-45.

11. Sivaneswaran S, Barnard PD. Periodontal assessment using the community periodontal index of treatment needs at Westmead Hospital, Sydney, 1984. Aust Dent J 1987;32:11-16.

12. Slade GD, Hoskin G. Provision of dental care to client groups. Chapter 7, In: Dental care for adults in Australia. Proceedings of a workshop. Adelaide: Adelaide University. 1993, 43-52.

13. Armstrong BK, White E, Saracci R. Principles of exposure measurement in epidemiology. Oxford University Press, 1994.

14. Slade GD. Methods. Chapter 2, In: Dental care for adults in Australia. Proceedings of a workshop. Adelaide: Adelaide University. 1993, 5-11.

15. AIHW Dental Statistics and Research Unit. New initiatives for dental surveys. Adelaide: Adelaide University, 1992.

16. Brennan DS, Carter KD, Stewart JF, Spencer AJ. Commonwealth dental health program evaluation report 1994-1996. Adelaide: Adelaide University, 1997.

17. Cons N, Beck JD, Field H, et al. A low-cost method for conducting a statewide survey of oral health. J Public Health Dent 1983;43:295-304.

18. Ainamo J, Barmes D, Beagrie G. Development of the World Health Organization (WHO) community periodontal index of treatment needs (CPITN). Int Dent J 1982;32:281-291.

19. Cutress TW, Ainamo J, Sardo-Infirri J. The community periodontal index of treatment needs (CPITN) procedure for population groups and individuals. Int Dent J 1987;37:222-233.

20. Cody RP, Smith JK. Applied statistics and the SAS programming language. New York: Elsevier, 1991.

21. Rural/remote areas classification. Canberra: Department of Human Services and Health, 1994.

22. SAS technical report p-200, SAS/STAT software: CALIS and LOGISTIC procedures, release 6.04. Cary, NC: SAS Institute Inc, 1990.

23. Clarkson JE, Worthington HV, Holloway PJ. Adult dental surveys: a different approach. Community Dent Health 1995;12:65-69.

24. Wright FAC, Hammond RH, Lewis JM. Changes in periodontal conditions of adults from Melbourne, Australia. Int Dent J 1994;44:207-214.

25. Baelum V, Papapanou PN. CPITN and the epidemiology of periodontal disease. Community Dent Oral Epidemiol 1996;24: 367-368.

26. Page RC, Morrison EC. Summary of outcomes and recommendations of the workshop on CPITN. Int Dent J 1994;44: 589-594.

27. Brennan DS, Spencer AJ, Slade GD. Provision of public dental services in urban, rural and remote locations. Community Dent Health 1996;13:157-162.

Address for correspondence/reprints: Professor AJ Spencer AIHW Dental Statistics and Research Unit Adelaide University Adelaide, South Australia 5005 